\title{
Implications of Managing Chronic Obstructive Pulmonary Disease in Cardiovascular Diseases
}

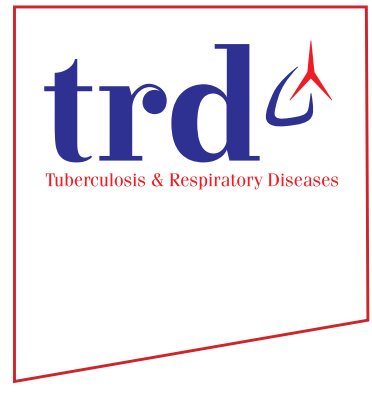

\author{
Kartik Deshmukh, M.B.B.S. ${ }^{1}$ (iD) and Arjun Khanna, D.M. ${ }^{2}$ \\ ${ }^{1}$ Fuqua School of Business, Duke University, Durham, NC, USA, ${ }^{2}$ Department of Pulmonary Medicine, Yashoda Hospital, Delhi, \\ India
}

Globally, cardiovascular diseases and chronic obstructive pulmonary disease (COPD) are the leading causes of the noncommunicable disease burden. Overlapping symptoms such as breathing difficulty and fatigue, with a lack of awareness about COPD among physicians, are key reasons for under-diagnosis and resulting sub-optimal care relative to COPD. Much has been published in the past on the pathogenesis and implications of cardiovascular comorbidities in COPD. However, a comprehensive review of the prevalence and impact of COPD management in commonly encountered cardiac diseases is lacking. The purpose of this study was to summarize the current knowledge regarding the prevalence of COPD in heart failure, ischemic heart disease, and atrial fibrillation. We also discuss the real-life clinical presentation and practical implications of managing COPD in cardiac diseases. We searched PubMed, Scopus, EMBASE, and Google Scholar for studies published 1981-May 2020 reporting the prevalence of COPD in the three specified cardiac diseases. COPD has high prevalence in heart failure, atrial fibrillation, and ischemic heart disease. Despite this, COPD remains under-diagnosed and under-managed in the majority of patients with cardiac diseases. The clinical implications of the diagnosis of COPD in cardiac disease includes the recognition of hyperinflation (a treatable trait), implementation of acute exacerbations of COPD (AECOPD) prevention strategies, and reducing the risk of overuse of diuretics. The pharmacological agents for the management of COPD have shown a beneficial effect on cardiac functions and mortality. The appropriate management of COPD improves the cardiovascular outcomes by reducing hyperinflation and preventing AECOPD, thus reducing the risk of mortality, improving exercise tolerance, and quality of life.

Keywords: Chronic Obstructive Pulmonary Disease; Heart Failure; Atrial Fibrillation; Ischemic Heart Disease; Hyperinflation; Cardiovascular Diseases; Spirometry; COPD-CVD

Address for correspondence: Kartik Deshmukh, M.B.B.S.

Fuqua School of Business, Duke University, Fuqua Drive, Durham, NC 27708, USA

Phone: 1-919-3089590, Fax: 1-919-3089590

E-mail: Kartik.deshmukh@duke.edu, Deshmukh.kartik333@gmail.com Received: Jul. 29, 2020

Revised: Aug. 31, 2020

Accepted: Oct. 13, 2020

Published online: Oct. 13, 2020

(9) It is identical to the Creative Commons Attribution Non-Commercial License (http://creativecommons.org/licenses/by-nc/4.0/).

Copyright $\odot 2021$

The Korean Academy of Tuberculosis and Respiratory Diseases.

\section{Introduction}

Globally, cardiovascular diseases and chronic obstructive pulmonary disease (COPD) are among the leading causes of non-communicable disease burden across the world ${ }^{1,2}$. These two diseases often occur in the same individual than what can be explained by chance alone. There has been a considerable awareness of cardiovascular diseases in the general population and clinicians. However, COPD remains neglected to this date. Over-lapping symptoms such as breathlessness and fatigue, coupled with a lack of awareness about COPD among physicians, are important reasons for under-diagnosis and resultant sub-optimal care in $\mathrm{COPD}^{3}$. Much has been published earlier on the pathogenesis and implications of cardiovascular co-morbidities in COPD, and even current Global Initiative for 
Chronic Obstructive Lung Disease (GOLD) 2020 guidelines highlight the importance of management of co-morbidities in COPD management $t^{4,5}$. However, a comprehensive review of prevalence and the impact of COPD management in commonly encountered cardiac diseases is lacking.

In this review, we have summarized the current knowledge regarding the prevalence of COPD in three common heart diseases: heart failure, atrial fibrillation, and ischemic heart disease. We have also stressed on the clinical implications of acute exacerbations of COPD (AECOPD) on cardiac disorders, and the need for considering COPD as a "treatable trait" in patients with COPD and cardiac diseases.

\section{Materials and Methods}

We searched PubMed, Scopus, EMBASE, and Google Scholar using the search terms "COPD and heart failure (HF)", "COPD and cardiovascular disease", "Airflow limitation and cardiac disease," "COPD and heart disease", "COPD and ischemia", "COPD and atrial fibrillation", and " $\mathrm{FEV}_{1}$ (forced expiratory volume at 1 second) and cardiovascular disease." We focused on studies and reports from 1981 to May 2020. We also searched the cross-references by the above- mentioned search strategy, and selected the relevant research articles.

\section{The current clinical scenario of COPD diagnosis}

There is an approximately $30 \%$ chance of detecting airway obstruction if the patient presents with ${ }^{6,7}$ (1) age $>35$ years, (2) smoker/ex-smoker/occupational exposure, (3) at-least one respiratory symptom (dyspnea, cough, wheeze, sputum, and/ or recurrent chest infections), and (4) frail elderly patients with complaints of dyspnea or exercise intolerance.

Not surprisingly, most of the patients with the symptoms mentioned above frequently present to a cardiology outpatient department, and hence the prevalence of COPD is higher in patients who visit a cardiologist (19.2\%) versus those who visit a primary care physician $(15.5 \%)^{8}$. Cuthbert et al. ${ }^{9}$ have reported a COPD prevalence of $35 \%$ using the GOLD diagnostic criteria $\left(\mathrm{FEV}_{1} /\right.$ forced vital capacity $\left.[\mathrm{FVC}]<0.7\right)$ for 4,986 patients referred from primary or secondary care to a community heart failure clinic. Despite this, spirometry in underutilized in cardiac practice ${ }^{10}$. Patients with a diagnosis of both COPD and HF are 20 times more likely to get a 2-D echo than spirometry ${ }^{11}$. In a study of 2,116 patients discharged from a tertiary care hospital with a diagnosis of COPD, HF, and COPD+HF, only $31 \%$ of COPD patients had had spirometry, as opposed to $78 \%$ of patients with HF who had a 2-D echo ${ }^{11}$.

COPD is associated with decreased daily life activity, even when airflow obstruction is only mildly to moderately impaired $^{12,13}$. Hence, many cardiac patients can have undiagnosed mild-moderate COPD, before they progress to a stage of severe COPD when the respiratory symptoms become very prominent $^{14,15}$.

\section{COPD in HF}

Cardiovascular health study was the first large scale study to confirm the increased prevalence of COPD (as diagnosed by American Thoracic Society (ATS) recommendations for spirometry, 1981) in HF (20\%) versus general population (13\%) $(p<0.05)^{16}$. Several large observational HF registries and randomized controlled trials (RCTs) have stated the prevalence of COPD in enrolled patients (Supplementary Tables S1 and S2). The prevalence of COPD seems slightly lower in RCTs as compared to observational studies because of strict inclusion criteria and exclusion criteria in RCTs.

A prevalence of up-to $52 \%$ (Kamalesh et al. ${ }^{17}$ ) and $41 \%$ (TEMISTOCLE) has been observed in the USA and European heart failure cohorts respectively ${ }^{17,18}$. The prevalence of COPD seems to be greater in recent studies vs studies conducted during the 1980s. Trends in HF epidemiology confirm the increasing prevalence of COPD in recent years ${ }^{19,20}$. This may be explained in part by greater awareness of COPD, and an aging population ${ }^{19}$. In a set of 207,984 patients enrolled in "Get with The Guidelines-Heart Failure Registry (GWTG)", COPD/ asthma was the second most common non-cardiovascular comorbidity (reported in $32 \%$ of enrolled patients) ${ }^{20}$. The same study also reported an increase in the prevalence of noncardiovascular comorbidities in HF from 2005-2014, with the greatest absolute increase (9\%) noticed in the prevalence of COPD/asthma.

In the majority of the heart failure studies, COPD is diagnosed based on the clinical judgment and medical records. This method is inaccurate since it has been shown that between $30 \%$ and $60 \%$ of patients with a previous physician diagnosis of COPD do not have the disease ${ }^{21}$. On the other hand, COPD is not diagnosed in up to $70 \%$ of patients who have the disease $^{21}$. Hence we looked at small studies that diagnosed COPD using spirometry in the HF population (Supplementary Table S3). Using the internationally accepted fixed ratio of $\mathrm{FEV}_{1} / \mathrm{FVC}<0.7$ to identify COPD in patients with heart failure, Bektas et al. ${ }^{22}$ and Arnaudis et al. ${ }^{23}$ diagnosed COPD in up-to $40 \%$ of stable HF patients and $37.9 \%$ of admitted HF patients respectively. The prevalence of COPD is considerably high in all HF populations, be it acute systolic failure or be it stable ambulatory HF.

Some studies recommend the use of the individual lower limit of normal (LLN), instead of the GOLD classification, to define COPD and prevent overdiagnosis of $\mathrm{COPD}^{24,25}$. Dalsgaard et al. ${ }^{26}$ evaluated the effects of cut-offs of fixed ratio $\left(\mathrm{FEV}_{1} / \mathrm{FVC}<0.7\right)$ and LLN on 593 patients in Heart Failure clinics. Of 593 patients, 228 (38\%) patients had $\mathrm{FEV}_{1} / \mathrm{FVC}$ $<0.7$ whereas 176 patients $(30 \%)$ had lung function values below LLN; the usage of fixed ratio resulted in overdiagnosis 
of COPD in $8 \%$ of the patients. This effect may be even more prominent in elderly HF patients.

Airflow obstruction is common in decompensated HF, and $\mathrm{HF}$ itself can cause a reduction of about $20 \%$ in $\mathrm{FEV}_{1}$ and $\mathrm{FVC}^{27,28}$. Airway obstruction can be a dynamic feature of $\mathrm{HF}$ that resolves with the achievement of euvolemia ${ }^{29}$. In stable euvolemic HF patients, both $\mathrm{FEV}_{1}$ and FVC decrease such that the ratio of $\mathrm{FEV}_{1} / \mathrm{FVC}$ is not affected prominently ${ }^{29,30}$. Hence it is essential to perform spirometry in euvolemic and stable $\mathrm{HF}$ patients.

There have been a lot of discussions lately on differences in heart failure with preserved ejection fraction (HFpEF) and heart failure with reduced ejection fraction (HFrEF). The pulmonary function is correlated with all-cause mortality in HFpEF patients; this effect is even seen in HFpEF patients without $\mathrm{COPD}^{31}$. COPD is an independent mortality predictor for HFpEF and HFrEF, but the mortality risk is higher for patients with $\mathrm{HFpEF}$ than with $\mathrm{HFrEF}^{32,33}$.

Probable reasons for increased prevalence and mortality of patients with COPD include (1) induction of pro-inflammatory state by COPD leads to cardiomyocyte and endothelial dysfunction ${ }^{34}$ and (2) impaired diastolic filling in patients with airflow limitation ${ }^{35}$.

Of the studies that documented COPD/asthma prevalence in these two categories of heart failure (Supplementary Table S4), the largest study has been GWTG which documented a prevalence of $33 \%$ in HFpEF and $27 \%$ in $\mathrm{HFrEF}^{36}$. Again, one of the important limitations of this study is the use of clinical judgment and/or medical records to diagnose COPD.

\section{COPD in ischemic heart disease}

There is substantial evidence to link COPD with atherosclerotic diseases. Smoking with abnormal $\mathrm{FEV}_{1} / \mathrm{FVC}$ ratio is significantly associated with severe carotid atherosclerosis among patients with ischemic heart disease (IHD) ${ }^{37}$. A significant association between airflow limitation and arterial stiffness has been reported in smokers from general population as well ${ }^{38}$. Airflow limitation in the general population is significantly associated with the development of hypertension in smokers ${ }^{39}$. Smokers with impaired pulmonary function tests have greater carotid intima medial thickness and a greater prevalence of carotid plaque as compared to smokers with normal pulmonary function ${ }^{40}$. Ankle-brachial index, often conventionally considered as a quick way to assess peripheral vascular disease, is correlated with pulmonary function tests even among never-smokers ${ }^{41,42}$. Not surprisingly, $23 \%$ of patients with cardiovascular diseases defined as coronary artery disease, cerebrovascular disease, peripheral vascular disease patients were reported to have spirometry confirmed COPD ${ }^{43}$.

COPD is twice as common in patients with IHD as in general population $\mathrm{IHD}^{44}$. Prevalence and under-diagnosis of airflow obstruction in patients of IHD are considerably high
(Supplementary Table S5). In a large study included patients with established IHD, 30.5\% of patients had COPD as diagnosed by GOLD criteria ${ }^{45}$. COPD is an important cause of refractory dyspnea in IHD patients, and failure to recognize this cause early often leads to unnecessary diagnostic tests and interventions ${ }^{46}$. In one analysis of patients of IHD treated by percutaneous coronary intervention, the prevalence of airway obstruction has been $\sim 25 \%{ }^{47}$. As in the case with HF, COPD in not diagnosed in up to $87 \%$ of patients with IHD and COPD $^{48}$. Patients with abnormal pulmonary function tests in IHD have been reported to have a poor quality of life, more symptoms, and poor exercise tolerance ${ }^{48}$.

COPD in myocardial infarction (MI) affects not only the components of physical health but also affects the psychological functioning of the patients ${ }^{48}$. In acute ST-elevation MI, COPD is a strong predictor of hemodynamic compromise. COPD decreases the capacity of the cardiovascular system to adjust to the effects of acute $\mathrm{MI}^{49}$.

\section{COPD in atrial fibrillation}

Atrial fibrillation (AF) is the most common arrhythmia encountered in clinical practice and is a leading cause of morbidity and mortality ${ }^{50}$. COPD is an important and underappreciated risk factor for atrial and ventricular arrhythmogenicity. The prevalence of COPD in atrial fibrillation varies depending on the patient population under consideration. Most studies with atrial fibrillation have reported COPD based on the clinical history and/or inhaled medications (Supplementary Table S6). We could locate only one large retrospective study of 7,990 patients with $\mathrm{AF}$ where the $\mathrm{FEV}_{1} / \mathrm{FVC}$ ratio was used for diagnosis; this study reported a COPD prevalence of $11.7 \%$ in patients with $\mathrm{AF}^{51}$. Presence and severity of COPD both are associated with increased likelihood of atrial fibrillation/ flutter versus those without COPD (23.3\% vs. $11.0 \%$, $\mathrm{p}<0.001)$, non-sustained ventricular tachycardia ( $13.0 \%$ vs. $5.9 \%$, $\mathrm{p}<0.001)$, and sustained ventricular tachycardia ( $0.9 \%$ vs. $1.6 \%$, $\mathrm{p}<0.001)^{52}$. Even in anti-coagulated patients with non-valvular AF, COPD has been associated with a $65 \%$ increased hazard of death ${ }^{53}$.

\section{Clinical implications of COPD in heart diseases}

\section{1) Treatable underfilling in heart failure with COPD: the relationship between the heart and lung vol- umes}

Hyperinflation is a major driver of COPD symptom burden and mortality. Hyperinflation reduces the efficiency of the respiratory muscles and is a major cause of dyspnea. Hyperinflation can be either static (loss of lung elastic recoil and destruction of lung parenchyma) or dynamic (air trapping with each additional breath). Parameters of Static hyperinflation have shown strong negative associations with cardiac chamber 
sizes $^{54,55}$. Inspiratory fraction (inspiratory capacity/total lung capacity), a marker of lung hyperinflation, was found to be an independent predictor of cardiac chamber size after adjustments for other potential confounders. Similar findings were demonstrated in the MESA COPD study where residual lung volume as measured by body plethysmography was associated with greater left ventricle mass on magnetic resonance imaging with a magnitude similar to that induced by systolic blood pressure ${ }^{54}$.

Airflow obstruction leads to lung hyperinflation, which in turn may cause increased pressures in the cardiopulmonary system. This leads to right-ventricular dysfunction, filling reductions in left ventricular end-diastolic volume, impaired left ventricle end-systolic volume, impaired stroke volume, and reduced cardiac output (Figure 1) 35,55,56. $^{3}$.

In the recent era of phenotyping, recognition, and management of lung hyperinflation in cardiac diseases as a "treatable trait" can improve cardiac function in patients with concomitant $\mathrm{COPD}^{57}$.

\section{2) AECOPD episodes}

Recurrent COPD exacerbations and resultant lung function decline lead to increased cardiovascular risk and mortality ${ }^{58,59}$. Vice versa, patients with COPD and cardiac diseases are more likely to exacerbate versus patients with COPD alone ${ }^{60}$.

Hypoxia and tachycardia during COPD exacerbations can impair Right Ventricular function, and aggravate underlying left ventricular dysfunction ${ }^{61}$. COPD exacerbation is also associated with autonomic dysfunction, that portends adverse cardiac outcomes $^{62}$. Cardiac muscle strain and injury during AECOPD lead to elevation of markers such as troponin T, Nterminal probrain natriuretic peptide (NT-proBNP). The levels of these markers correlate well with short-term and long-term mortality in patient who have an AECOPD episode ${ }^{63}$. Patients with AECOPD are more likely to have significantly longer total atrial conduction time estimated via tissue Doppler imaging (PA-TDI) interval (total atrial conduction time via tissue Doppler imaging), and to develop atrial fibrillation versus patients with stable COPD with comparable NT-proBNP, left ventricular function and atrial sizes ${ }^{64}$. In a study of AECOPD patients hospitalized for hypercapnic respiratory failure, the risk of new AF was correlated with Impaired pulmonary function, hypercapnia, and increased pulmonary artery systolic pressure $^{65}$.

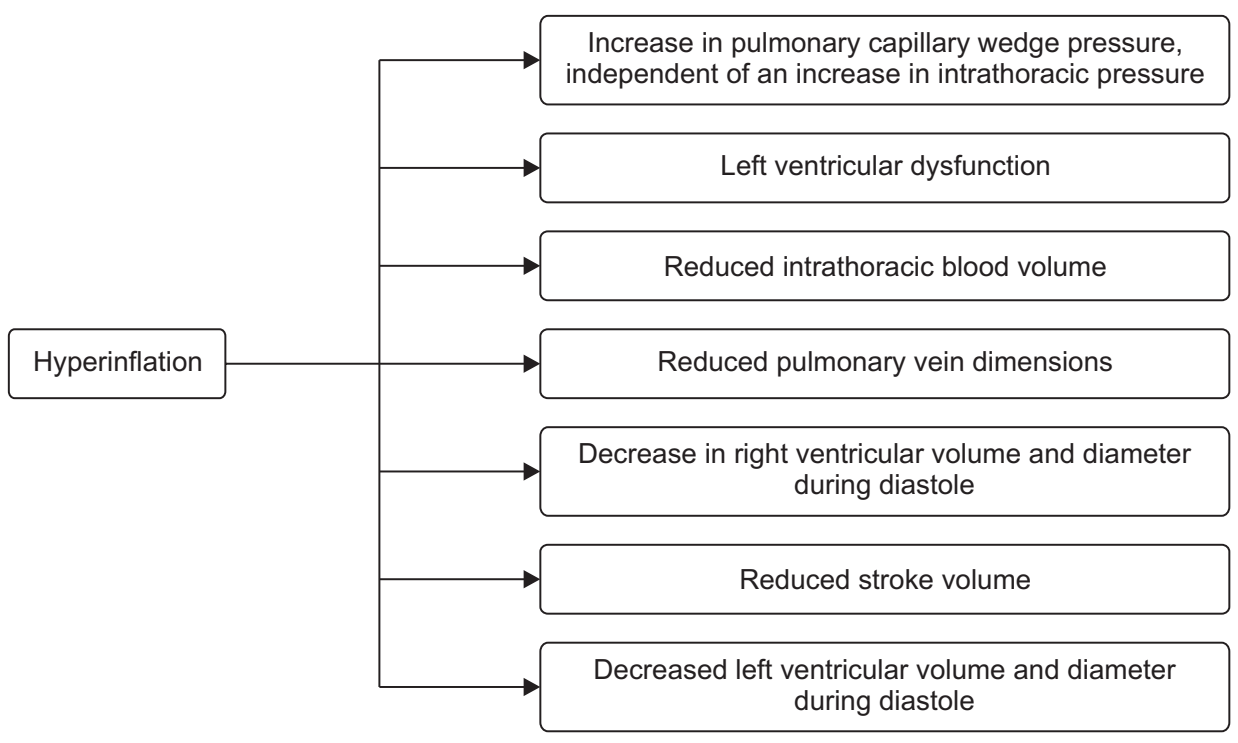

Figure 1. Effects of hyperinflation on cardiovascular system.

Table 1. Risk of adverse outcomes after an acute exacerbation of chronic obstructive pulmonary disease ${ }^{66}$

\begin{tabular}{|lcc|}
\hline \multicolumn{1}{|c}{ Outcome } & Incidence rate ratio after 30 days & Incidence rate ratio after $\mathbf{1}$ year \\
\hline Acute myocardial infarction & $1.28(1.17-1.39)$ & $1.10(1.05-1.15)$ \\
Heart failure & $1.25(1.20-1.30)$ & $1.20(1.17-1.22)$ \\
Atrial fibrillation & $1.52(1.39-1.66)$ & $1.19(1.14-1.25)$ \\
Pulmonary embolism & $1.89(1.65-2.17)$ & $1.27(1.18-1.37)$ \\
\hline Ischemic stroke & $1.77(1.55-2.01)$ & $1.39(1.30-1.47)$ \\
Hemorrhagic stroke & $1.73(1.18-2.54)$ & $1.71(1.45-2.02)$ \\
\hline
\end{tabular}


In a large population-based study with data of 362,827 patients, AECOPD has been associated with increased hospitalizations and emergency department visits for cardiovascular events at 30 days and 1-year post-AECOPD episode (Table 1$)^{66}$.

Another study of 25,857 COPD patients in England reported that AECOPD is associated with 2.27 -fold (95\% confidence interval, 1.1-4.7; $\mathrm{p}=0.03$ ) increased risk of $\mathrm{MI}$ and 1.26-fold (95\% confidence interval, 1.0-1.6; $\mathrm{p}=0.05$ ) increased risk of stroke $^{58}$. The increased risk after AECOPD is apparent as early as 5 days and 49 days after an exacerbation in case of MI and stroke respectively. The severity of exacerbation is an additional factor to consider. Increasing severity of AECOPD episode leads to subsequently increased risk of $\mathrm{MI}$ and ischemic stroke $^{67}$.

A COPD patient with an AECOPD episode is at a higher risk of stroke as compared to patient with COPD and no exacerbation episode (hazard ratio, 6.66; 95\% confidence interval, 2.42-18.20 ${ }^{68}$. Acute episode of AECOPD leads to systemic hypoxia, increased arterial stiffness, and increased systemic inflammation ${ }^{58,60,61}$. Hypoxia during AECOPD contributes to endothelial damage and, along with increased thrombogenic inflammatory mediators, may lead to vascular abnormalities and adverse cardiovascular outcomes (Figure 2) ${ }^{58,61}$. Repeated AECOPD may lead to increased pulmonary artery pressure and increase the right heart strain, and this may worsen the existing cardiac disorders ${ }^{65}$. Hence, prevention of AECOPD remains a useful strategy.

\section{3) Benefit on physiological and psychological param- eters}

There is considerable evidence which suggests that the ap- propriate management of COPD in cardiac diseases has a substantial benefit on physiological and psychological parameters. Guideline based treatment of COPD in cardiovascular disease has been shown to improve lung function, quality of life and exercise intolerance ${ }^{45}$.

\section{4) Avoidance of inappropriate diuretic use}

Breathless in a common symptom in heart disease, and leads to prescription of diuretics. The knowledge of patients having COPD may reduce the risk of over-using diuretics due to misinterpretation of cause of increased/refractory/persistent dyspnea in patients with COPD with heart disease. Appropriate management of COPD in such patients will improve breathlessness and reduce the risk of complications such as electrolyte imbalance associated with diuretic prescription.

Hence it seems relevant to perform spirometry-a simple, cost-effective, non-invasive, and objective examination-in all patients with HF, AF, and IHD. The decline of cardiovascular function sets in before the development of symptomatic $\mathrm{COPD}^{69}$. The words such as "mild COPD", "asymptomatic COPD" are deceiving since many individuals self-restrict activity to minimize symptoms. Undiagnosed COPD leads to an increased risk for all-cause mortality, and increased resource utilization compared to those without $\mathrm{COPD}^{70}$.

\section{Effects of pharmacological interventions for COPD on cardiovascular function}

There is an ongoing debate for a long time regarding the cardiovascular safety of drugs for COPD. Many studies have been conducted for addressing the debate, and sometimes,

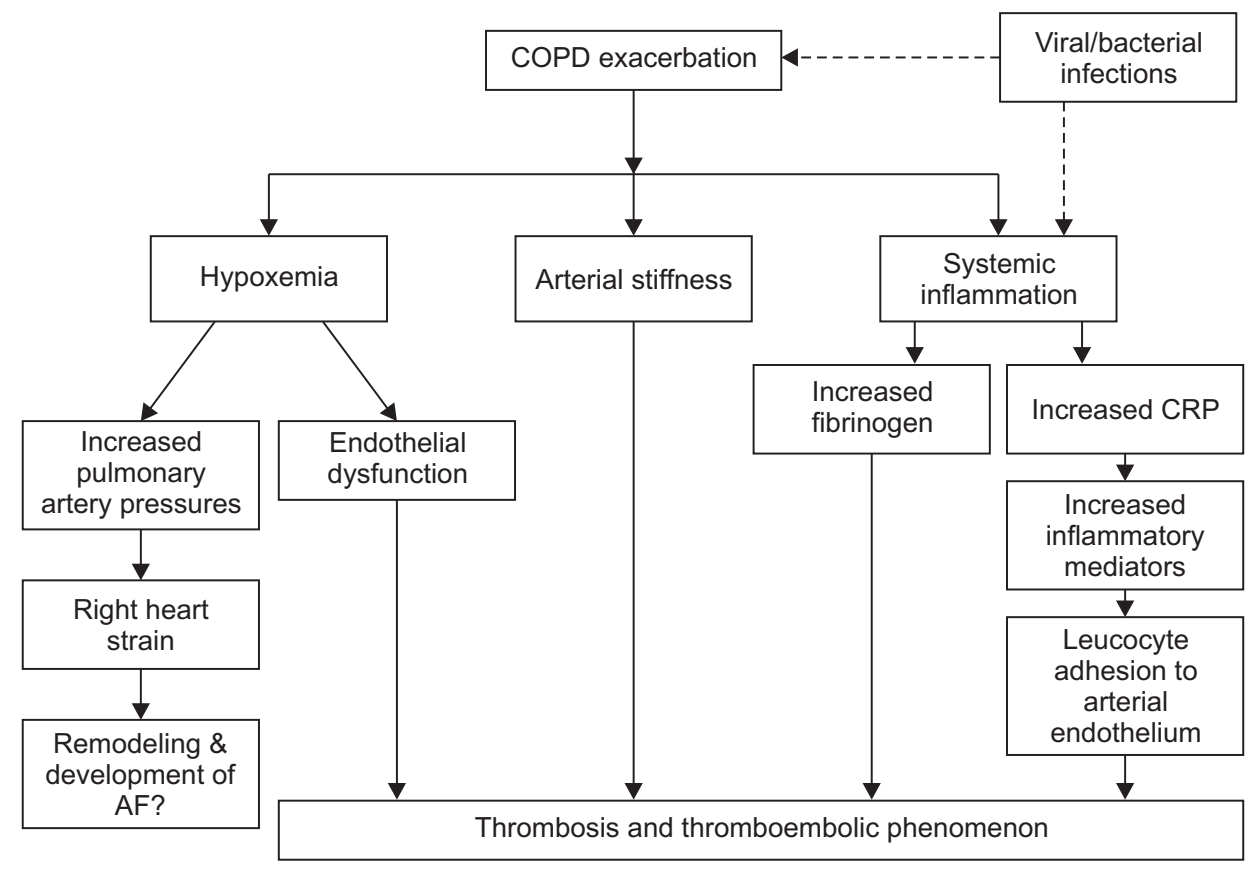

Figure 2. Plausible mechanisms to explain the increased risk of adverse cardiac events with acute exacerbations of chronic obstructive pulmonary disease episodes. AF: atrial fibrillation; COPD: chronic obstructive pulmonary disease; CRP: C-reactive protein. 
have produced conflicting results. While we have reviewed the safety concerns and the adverse event data with pharmacotherapy for COPD, we haven't focused on that aspect in the current review. It has been proven beyond doubt to diagnose and manage COPD in patients with cardiovascular diseases. Mahendra et al. ${ }^{48}$ screened COPD in patients with IHD, and demonstrated that guideline-based COPD management in these patients resulted in better control of symptoms and improved quality of life. We have summarized below some pharmacotherapies in COPD, which have been shown to improve cardiac function and/or cardiovascular outcomes.

\section{1) Inhaled therapies}

Inhaled therapy is the cornerstone of pharmacotherapy for COPD management. GOLD 2020 highlights the use of bronchodilators as first-line therapy for COPD ${ }^{5}$. Bronchodilators include long-acting beta-agonist (LABA), long-acting muscarinic antagonist (LAMA), or a combination of LABA-LAMA. Bronchodilators have been shown to reduce Hyperinflation, an important "treatable trait", and improve breathlessness, and cardiac function. In patients with stable COPD, bronchodilators lead to lung deflation and improve perfusion ratio (discussed below). This is turn leads to improved cardiac output, and reduced risk of deleterious ventricular re-modeling (Figure 3). Bronchodilators also prevent AECOPD, which leads to an increased risk of adverse cardiovascular events.

(1) LAMA: Tiotropium, a LAMA, has been shown to improve hyperinflation and cardiovascular responses to exercise in COPD patients ${ }^{71}$. There is evidence with tiotropium to suggest that it improves left ventricular diastolic function in COPD patients ${ }^{72}$. Data from large scale RCT indicates that tiotropium is associated with decreased all-cause cardiovascular and respiratory mortality ${ }^{55}$.

(2) LABA-LAMA: Recently published ATS guidelines for COPD have recommended LAMA-LABA as initial therapy for COPD patients who have significant dyspnea and exercise intolerance $^{73}$. Often the therapy needs to be escalated from a single LAMA to a LAMA-LABA combination because of lack of optimal control with mono-bronchodilator or inhaled corticosteroid (ICS)-LABA therapy.

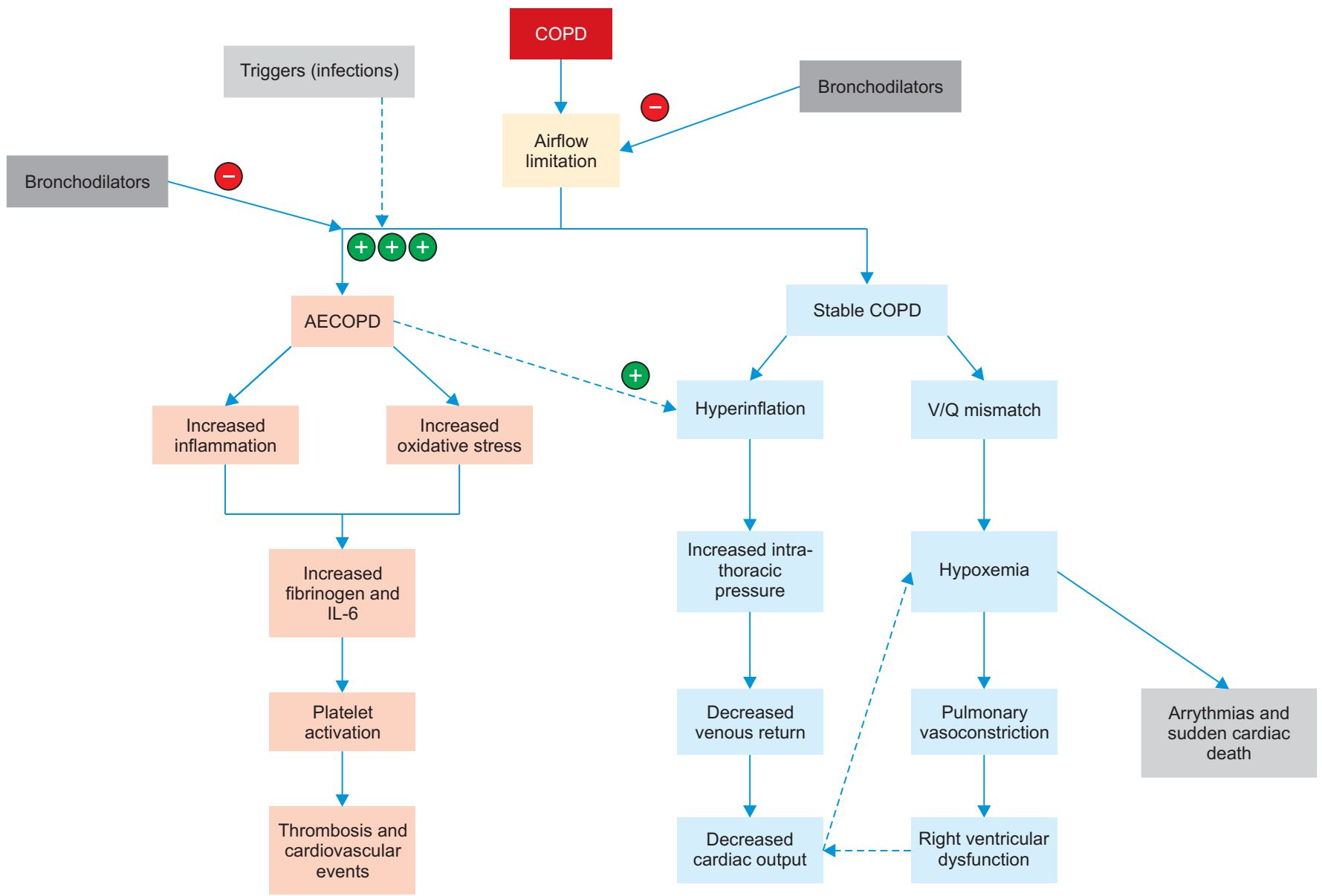

Figure 3. Effect of bronchodilators on hyperinflation and AECOPD. AECOPD: acute exacerbations of chronic obstructive pulmonary disease; COPD: chronic obstructive pulmonary disease; IL-6: interleukin 6. 
The effects of LABA-LAMA on hyperinflation and cardiac system in COPD are as follows ${ }^{74-77}:(1)$ increased exercise tolerance, (2) attenuation of dynamic hyperinflation, (3) improved pulmonary microvascular blood flow and regional ventilation, (4) improved left-ventricular and right ventricular end-diastolic volume, and (5) increased left ventricular and right ventricular stroke volume.

(3) ICS-LABA: LABA-ICS combinations, though not advocated by guidelines as the primary treatment, are often widely prescribed in COPD, especially in primary care practice. Recently, it has been shown that administration of Budesonide/ Formoterol results in significant reduction of hyperinflation, an increase in oxygen uptake, and minute ventilation at lower lung volumes, thereby potentially improving cardiac function as well ${ }^{78}$. A new LABA-ICS combination, fluticasone furoate/ vilanterol, has been shown to reduce lung hyperinflation and improve right ventricular end-diastolic volume index, Left ventricular end-diastolic volume, and left atrial end-systolic volume, right ventricular stroke volume, and left atrial ejection fraction versus placebo ${ }^{79}$. In the SUMMIT trial that enrolled 16,590 patients with moderate COPD and increased cardiovascular risk (SUMMIT), treatment with fluticasone furoate and vilanterol did not lead to excess mortality or worsening of cardiovascular outcomes. Fluticasone furoate and vilanterol in a single inhaler once daily reduced exacerbations frequency and was well tolerated in the study population ${ }^{80}$.

(4) ICS-LAMA-LABA: ICS-LAMA-LABA combinations or "triple therapy" provide the benefit of combining dual bronchodilators with ICS, thereby potentially reducing the hyperinflation and recurrent AECOPD episodes. Recently, it has been shown that reduction of exacerbation by triple therapy in COPD translates in mortality benefits. Fluticasone/ vilanterol/umeclidinium has also been shown to reduce allcause mortality with lower rates of cardiovascular and respiratory deaths ${ }^{81}$.

\section{2) Oral therapy}

(1) Roflumilast: Roflumilast, an oral drug, is indicated for COPD patients with frequent exacerbation $\mathrm{s}^{5,82}$. Lower rate of cardiovascular events was observed with Roflumilast vs placebo in a subset analysis (hazard ratio, $0.65 ; 95 \%$ confidence intervals, $0.45-0.93 ; p=0.019)$. In some cases, the effect on cardiovascular events was apparent as early as 90 days after the start of the therapy. The reduction in adverse cardiovascular events with roflumilast has been attributed to a reduction in vascular inflammation induced by phosphodiesterase 4 inhibition $^{83}$.

\section{Effects of non-pharmacological interventions for COPD on cardiovascular function}

Non-pharmacological interventions are currently recommended as the essential component of treatment protocol for
$\mathrm{COPD}^{5}$. Breathlessness is a common symptom of cardiac disease and COPD, with immobility and skeletal muscle modification an important factor contributing to further worsening of breathlessness ${ }^{84}$. Activity limitation is an important aspect of both COPD and heart failure. Lack of activity leads to poor prognosis, and poor quality of life in these patients ${ }^{85}$. Exercise training, as a part of pulmonary rehabilitation program, improves physical activity and reduces anxiety in patients ${ }^{86}$. In a small study, pulmonary rehabilitation has been shown to reduce the heart rate and aortic wave velocity in COPD patients ${ }^{87}$. Patients with COPD and heart failure enrolled in pulmonary rehabilitation program demonstrated significant improvement in health-related quality of life and exercise tolerance ${ }^{87}$. There is considerable evidence to suggest that pulmonary rehabilitation in patients with cardiovascular disorders is safe as well ${ }^{88}$.

\section{Conclusion}

COPD has a high prevalence in heart failure, atrial fibrillation, and ischemic heart disease. Despite this, COPD remains under-diagnosed and under-managed in the majority of patients with cardiac diseases. Guideline based management of COPD can improve cardiovascular outcomes. Clinical implications of the diagnosis of COPD in cardiac disease include recognition of hyperinflation (a treatable trait), implementation of AECOPD prevention strategies, and reducing the risk of overuse of diuretics. Hence, spirometry should be performed in every patient with cardiac disease. There is enough evidence of the beneficial effects of pharmacological agents for COPD management on cardiac functions and mortality. Appropriate management of COPD improves the cardiovascular outcomes by reducing hyperinflation and preventing AECOPD, thereby reducing the risk of mortality, improving exercise tolerance, and quality of life.

\section{Authors' Contributions}

Conceptualization: Deshmukh K, Khanna A. Methodology: Deshmukh K, Khanna A. Data curation: Deshmukh K, Khanna A. Investigation: Deshmukh K, Khanna A. Writing original draft preparation: Deshmukh K, Khanna A. Writing review and editing: Deshmukh K, Khanna A. Approval of final manuscript: all authors.

\section{Conflicts of Interest}

No potential conflict of interest relevant to this article was reported. 


\section{Funding}

No funding to declare.

\section{Supplementary Material}

Supplementary material can be found in the journal homepage (http://www.e-trd.org).

Supplementary Table S1. Prevalence of COPD in observational heart failure registries/studies.

Supplementary Table S2. Prevalence of COPD in randomized controlled trials in HF.

Supplementary Table S3. Prevalence of COPD in HF as diagnosed by $\mathrm{FEV}_{1} / \mathrm{FVC}$ ratio.

Supplementary Table S4. Prevalence of COPD in HFpEF and HFrEF.

Supplementary Table S5. Prevalence of COPD in IHD.

Supplementary Table S6. Prevalence of COPD in atrial fibrillation.

\section{References}

1. GBD 2016 Disease and Injury Incidence and Prevalence Collaborators. Global, regional, and national incidence, prevalence, and years lived with disability for 328 diseases and injuries for 195 countries, 1990-2016: a systematic analysis for the Global Burden of Disease Study 2016. Lancet 2017;390: 1211-59.

2. Park YB, Rhee CK, Yoon HK, Oh YM, Lim SY, Lee JH, et al. Revised (2018) COPD Clinical Practice Guideline of the Korean Academy of Tuberculosis and Respiratory Disease: a summary. Tuberc Respir Dis 2018;81:261-73.

3. Ragaisiene G, Kibarskyte R, Gauronskaite R, Giedraityte M, Dapsauskaite A, Kasiulevicius V, et al. Diagnosing COPD in primary care: what has real life practice got to do with guidelines? Multidiscip Respir Med 2019;14:28.

4. Morgan AD, Zakeri R, Quint JK. Defining the relationship between COPD and CVD: what are the implications for clinical practice? Ther Adv Respir Dis 2018;12:1753465817750524.

5. Global Initiative for Chronic Obstructive Lung Disease [Internet]. Fontana: Global Initiative for Chronic Obstructive Lung Disease; 2020 [cited 2020 Aug 10]. Available from: https:// goldcopd.org/.

6. Ulrik CS, Lokke A, Dahl R, Dollerup J, Hansen G, Cording PH, et al. Early detection of COPD in general practice. Int J Chron Obstruct Pulmon Dis 2011;6:123-7.

7. Bertens LC, Reitsma JB, van Mourik Y, Lammers JW, Moons $\mathrm{KG}$, Hoes AW, et al. COPD detected with screening: impact on patient management and prognosis. Eur Respir J 2014;44: 1571-8.

8. Heredia D, Renner-Carmona JL, Rosales L, Romelus A,
Mendes ES, Campos M. Prevalence and Underdiagnosis of COPD: a comparison between primary care and cardiology clinics. Am J Respir Crit Care Med 2012;185:A2308.

9. Cuthbert JJ, Kearsley JW, Kazmi S, Kallvikbakka-Bennett A, Weston J, Davis J, et al. The impact of heart failure and chronic obstructive pulmonary disease on mortality in patients presenting with breathlessness. Clin Res Cardiol 2019;108:18593.

10. Zaas D, Wise R, Wiener C; Longcope Spirometry Invetigation Team. Airway obstruction is common but unsuspected in patients admitted to a general medicine service. Chest 2004;125:106-11.

11. Damarla M, Celli BR, Mullerova HX, Pinto-Plata VM. Discrepancy in the use of confirmatory tests in patients hospitalized with the diagnosis of chronic obstructive pulmonary disease or congestive heart failure. Respir Care 2006;51:1120-4.

12. O'Donnell DE, Gebke KB. Activity restriction in mild COPD: a challenging clinical problem. Int J Chron Obstruct Pulmon Dis 2014;9:577-88.

13. Han Y, Heo Y, Hong Y, Kwon SO, Kim WJ. Correlation between physical activity and lung function in dusty areas: results from the Chronic Obstructive Pulmonary Disease in Dusty Areas (CODA) cohort. Tuberc Respir Dis 2019;82:311-8.

14. Minasian A, Dekhuijzen R, Van den Elshout F, Vos P, Willems F, Van den Bergh P, et al. COPD prevalence in chronic heart failure. Eur Respir J 2011;38:1019.

15. Kolacinska-Flont M, Drozdz J, Zielinska M, Kuprys-Lipinska I, Kuna P. Asthma and COPD in patients with coronary artery disease: the unmet demands. Eur Respir J 2016;48:OA256.

16. Kitzman DW, Gardin JM, Gottdiener JS, Arnold A, Boineau $\mathrm{R}$, Aurigemma G, et al. Importance of heart failure with preserved systolic function in patients $>$ or $=65$ years of age. CHS Research Group. Cardiovascular Health Study. Am J Cardiol 2001;87:413-9.

17. Kamalesh M, Subramanian U, Sawada S, Eckert G, Temkit M, Tierney W. Decreased survival in diabetic patients with heart failure due to systolic dysfunction. Eur J Heart Fail 2006;8:4048.

18. Di Lenarda A, Scherillo M, Maggioni AP, Acquarone N, Ambrosio GB, Annicchiarico M, et al. Current presentation and management of heart failure in cardiology and internal medicine hospital units: a tale of two worlds: the TEMISTOCLE study. Am Heart J 2003;146:E12.

19. Hawkins NM, Petrie MC, Jhund PS, Chalmers GW, Dunn FG, McMurray JJ. Heart failure and chronic obstructive pulmonary disease: diagnostic pitfalls and epidemiology. Eur J Heart Fail 2009;11:130-9.

20. Sharma A, Zhao X, Hammill BG, Hernandez AF, Fonarow GC, Felker GM, et al. Trends in noncardiovascular comorbidities among patients hospitalized for heart failure: insights from the get with the guidelines-heart failure registry. Circ Heart Fail 2018;11:e004646.

21. Diab N, Gershon AS, Sin DD, Tan WC, Bourbeau J, Boulet LP, 
et al. Underdiagnosis and overdiagnosis of chronic obstructive pulmonary disease. Am J Respir Crit Care Med 2018;198: 1130-9.

22. Bektas S, Franssen FM, van Empel V, Uszko-Lencer N, Boyne J, Knackstedt C, et al. Impact of airflow limitation in chronic heart failure. Neth Heart J 2017;25:335-42.

23. Arnaudis B, Lairez O, Escamilla R, Fouilloux A, Fournier P, Monteil B, et al. Impact of chronic obstructive pulmonary disease severity on symptoms and prognosis in patients with systolic heart failure. Clin Res Cardiol 2012;101:717-26.

24. Rutten FH, Cramer MJ, Lammers JW, Grobbee DE, Hoes AW. Heart failure and chronic obstructive pulmonary disease: An ignored combination? Eur J Heart Fail 2006;8:706-11.

25. Le Jemtel TH, Padeletti M, Jelic S. Diagnostic and therapeutic challenges in patients with coexistent chronic obstructive pulmonary disease and chronic heart failure. J Am Coll Cardiol 2007;49:171-80.

26. Dalsgaard M, Plesner LL, Schou M, Kjoller E, Vestbo J, Iversen K. Prevalence of airflow obstruction in patients with stable systolic heart failure. BMC Pulm Med 2017;17:6.

27. Petermann W, Barth J, Entzian P. Heart failure and airway obstruction. Int J Cardiol 1987;17:207-9.

28. Guder G, Rutten FH, Brenner S, Angermann CE, Berliner D, Ertl G, et al. The impact of heart failure on the classification of COPD severity. J Card Fail 2012;18:637-44.

29. Minasian AG, van den Elshout FJ, Dekhuijzen PR, Vos PJ, Willems FF, van den Bergh PJ, et al. Serial pulmonary function tests to diagnose COPD in chronic heart failure. Transl Respir Med 2014;2:12.

30. Guder G, Rutten FH. Comorbidity of heart failure and chronic obstructive pulmonary disease: more than coincidence. Curr Heart Fail Rep 2014;11:337-46.

31. Huang WM, Cheng HM, Shiao TH, Chen CH, Yu WC, Sung $\mathrm{SH}$. The role pulmonary function test in patients with heart failure with preserved ejection fraction: looking beyond chronic obstruction pulmonary disease. J Am Coll Cardiol 2017;69(11 Suppl):878.

32. Ather S, Chan W, Bozkurt B, Aguilar D, Ramasubbu K, Zachariah AA, et al. Impact of noncardiac comorbidities on morbidity and mortality in a predominantly male population with heart failure and preserved versus reduced ejection fraction. J Am Coll Cardiol 2012;59:998-1005.

33. Berry C, Hogg K, Norrie J, Stevenson K, Brett M, McMurray J. Heart failure with preserved left ventricular systolic function: a hospital cohort study. Heart 2005;91:907-13.

34. Mentz RJ, Kelly JP, von Lueder TG, Voors AA, Lam CS, Cowie $\mathrm{MR}$, et al. Noncardiac comorbidities in heart failure with reduced versus preserved ejection fraction. J Am Coll Cardiol 2014;64:2281-93.

35. Barr RG, Bluemke DA, Ahmed FS, Carr JJ, Enright PL, Hoffman EA, et al. Percent emphysema, airflow obstruction, and impaired left ventricular filling. N Engl J Med 2010;362:21727.
36. Steinberg BA, Zhao X, Heidenreich PA, Peterson ED, Bhatt DL, Cannon CP, et al. Trends in patients hospitalized with heart failure and preserved left ventricular ejection fraction: prevalence, therapies, and outcomes. Circulation 2012;126: 65-75.

37. Hamrah MS, Suzuki S, Ishii H, Shibata Y, Tatami Y, Osugi N, et al. Impact of airflow limitation on carotid atherosclerosis in coronary artery disease patients. Respiration 2015;89:322-8.

38. Tabara Y, Muro S, Takahashi Y, Setoh K, Kawaguchi T, Terao C, et al. Airflow limitation in smokers is associated with arterial stiffness: the Nagahama Study. Atherosclerosis 2014;232:5964.

39. Takase H, Machii M, Nonaka D, Sugiura T, Yamashita S, Ohte $\mathrm{N}$, et al. Does airflow limitation predict the future hypertension in the normotensive general population? Eur Heart J 2017;38(Suppl 1):ehx504.P4426.

40. Iwamoto H, Yokoyama A, Kitahara Y, Ishikawa N, Haruta Y, Yamane $\mathrm{K}$, et al. Airflow limitation in smokers is associated with subclinical atherosclerosis. Am J Respir Crit Care Med 2009;179:35-40.

41. Schroeder EB, Welch VL, Evans GW, Heiss G. Impaired lung function and subclinical atherosclerosis. The ARIC Study. Atherosclerosis 2005;180:367-73.

42. Tuleta I, Farrag T, Busse L, Pizarro C, Schaefer C, Pingel S, et al. High prevalence of COPD in atherosclerosis patients. Int J Chron Obstruct Pulmon Dis 2017;12:3047-53.

43. Muralimohan BV, Ekbote G, Tousheed SZ, Ramanjenaya R. Prevalence of COPD in vascular diseases. Eur Respir J 2015; 46:PA1131.

44. Soriano JB, Rigo F, Guerrero D, Yanez A, Forteza JF, Frontera $\mathrm{G}$, et al. High prevalence of undiagnosed airflow limitation in patients with cardiovascular disease. Chest 2010;137:333-40.

45. Franssen FM, Soriano JB, Roche N, Bloomfield PH, Brusselle G, Fabbri LM, et al. Lung function abnormalities in smokers with ischemic heart disease. Am J Respir Crit Care Med 2016; 194:568-76.

46. Mihailichenko D, Pertseva T. COPD as undetected cause of dyspnea in patients admitted with ischaemic heart disease (IHD). Eur Respir J 2014;44:P3638.

47. Navarro A, Lapuente AM, Pareja J, Barrera A, Yun S, De La Sierra A, et al. Prevalence and underdiagnosis of COPD in patients with ischemic heart disease demonstrated by coronary angiography: prognostic implications. Eur Respir J 2015;46: PA4807.

48. Mahendra M, S SK, Desai N, Bs J, Pa M. Evaluation for airway obstruction in adult patients with stable ischemic heart disease. Indian Heart J 2018;70:266-71.

49. Wakabayashi K, Gonzalez MA, Delhaye C, Ben-Dor I, Maluenda G, Collins SD, et al. Impact of chronic obstructive pulmonary disease on acute-phase outcome of myocardial infarction. Am J Cardiol 2010;106:305-9.

50. Wyndham CR. Atrial fibrillation: the most common arrhythmia. Tex Heart Inst J 2000;27:257-67. 
51. Rodriguez-Manero M, Lopez-Pardo E, Cordero A, RuanoRavina A, Novo-Platas J, Pereira-Vazquez M, et al. A prospective study of the clinical outcomes and prognosis associated with comorbid COPD in the atrial fibrillation population. Int J Chron Obstruct Pulmon Dis 2019;14:371-80.

52. Konecny T, Park JY, Somers KR, Konecny D, Orban M, Soucek F, et al. Relation of chronic obstructive pulmonary disease to atrial and ventricular arrhythmias. Am J Cardiol 2014;114: 272-7.

53. Pokorney SD, Piccini JP, Stevens SR, Patel MR, Pieper KS, Halperin JL, et al. Cause of death and predictors of all-cause mortality in anticoagulated patients with nonvalvular atrial fibrillation: data from ROCKET AF. J Am Heart Assoc 2016;5: e002197.

54. Smith BM, Kawut SM, Bluemke DA, Basner RC, Gomes AS, Hoffman E, et al. Pulmonary hyperinflation and left ventricular mass: the Multi-Ethnic Study of Atherosclerosis COPD Study. Circulation 2013;127:1503-11.

55. Rabe KF, Hurst JR, Suissa S. Cardiovascular disease and COPD: dangerous liaisons? Eur Respir Rev 2018;27:180057.

56. Watz H. Chronic obstructive pulmonary disease: when pulmonologists do something good for the heart. Am J Respir Crit Care Med 2016;193:703-4.

57. Alter P, Watz H, Kahnert K, Pfeifer M, Randerath WJ, Andreas S, et al. Airway obstruction and lung hyperinflation in COPD are linked to an impaired left ventricular diastolic filling. Respir Med 2018;137:14-22.

58. Donaldson GC, Hurst JR, Smith CJ, Hubbard RB, Wedzicha JA. Increased risk of myocardial infarction and stroke following exacerbation of COPD. Chest 2010;137:1091-7.

59. Park HJ, Kim SH, Kim HC, Lee BY, Lee SW, Lee JS, et al. Utility of computed tomography in a differential diagnosis for the patients with an initial diagnosis of chronic obstructive pulmonary disease exacerbation. Tuberc Respir Dis 2019;82:23441.

60. Kchaou K, Kammoun R, Chaabouni M, Trabelsi H, Triki L, Kammoun I, et al. Impact of concomitant cardiovascular diseases on functional status and quality of life of patients with chronic obstructive pulmonary disease. Eur Respir J 2019;54: PA4489.

61. Ozben B, Eryuksel E, Tanrikulu AM, Papila N, Ozyigit T, Celikel T, et al. Acute exacerbation impairs right ventricular function in COPD patients. Hellenic J Cardiol 2015;56:324-31.

62. Adam O, Ukena C, Bohm M, Neuberger HR. Bidirectional ventricular tachycardia in a patient with exacerbation of chronic obstructive pulmonary disease. Clin Res Cardiol 2012;101:851-2.

63. Shafuddin E, Chang CL, Cooray M, Tuffery CM, Hopping SJ, Sullivan GD, et al. Changes in biomarkers of cardiac dysfunction during exacerbations of chronic obstructive pulmonary disease. Respir Med 2018;145:192-9.

64. Hemat A, Muller P, Jung C, Kruger S, Keymel S. Increased risk of atrial fibrillation in patients with acute exacerbation of chronic obstructive pulmonary disease and sinus rhythm. Eur Respir J 2018;52:PA745.

65. Terzano C, Romani S, Conti V, Paone G, Oriolo F, Vitarelli A. Atrial fibrillation in the acute, hypercapnic exacerbations of COPD. Eur Rev Med Pharmacol Sci 2014;18:2908-17.

66. Goto T, Shimada YJ, Faridi MK, Camargo CA Jr, Hasegawa K. Incidence of acute cardiovascular event after acute exacerbation of COPD. J Gen Intern Med 2018;33:1461-8.

67. Rothnie KJ, Connell O, Mullerova H, Smeeth L, Pearce N, Douglas I, et al. Myocardial infarction and ischemic stroke after exacerbations of chronic obstructive pulmonary disease. Ann Am Thorac Soc 2018;15:935-46.

68. Portegies ML, Lahousse L, Joos GF, Hofman A, Koudstaal PJ, Stricker BH, et al. Chronic obstructive pulmonary disease and the risk of stroke. The Rotterdam Study. Am J Respir Crit Care Med 2016;193:251-8.

69. Cao J, Halloran K, Cheng J, Passick M, Ngai N. Adverse cardiac and pulmonary vascular change in patients with subclinical and clinical COPD. Circulation 2014;130(Suppl 2):A15873.

70. Labaki WW, Han MK. Improving detection of early chronic obstructive pulmonary disease. Ann Am Thorac Soc 2018; 15(Suppl 4):S243-8.

71. Travers J, Laveneziana P, Webb KA, Kesten S, O'Donnell DE. Effect of tiotropium bromide on the cardiovascular response to exercise in COPD. Respir Med 2007;101:2017-24.

72. Nojiri T, Yamamoto K, Maeda H, Takeuchi Y, Funakoshi Y, Maekura R, et al. Effects of inhaled tiotropium on left ventricular diastolic function in chronic obstructive pulmonary disease patients after pulmonary resection. Ann Thorac Cardiovasc Surg 2012;18:206-11.

73. Nici L, Mammen MJ, Charbek E, Alexander PE, Au DH, Boyd $\mathrm{CM}$, et al. Pharmacologic management of chronic obstructive pulmonary disease: an Official American Thoracic Society Clinical Practice Guideline. Am J Respir Crit Care Med 2020;201:e56-69.

74. Stringer W, Porszasz J, Von Plato M, Khosrovi-Eghbal A, Zopey M, Cao M, et al. A randomized trial to determine th-e effect of glycopyrrolate/formoterol on exercise tolerance in COPD: influence of dynamic hyperinflation and dead space ventilation. Eur Respir J 2019;54:OA259.

75. Vogel-Claussen J, Schonfeld CO, Kaireit TF, Voskrebenzev A, Czerner CP, Renne J, et al. Effect of indacaterol/glycopyrronium on pulmonary perfusion and ventilation in hyperinflated patients with chronic obstructive pulmonary disease (CLAIM): a double-blind, randomized, crossover trial. Am J Respir Crit Care Med 2019;199:1086-96.

76. Hohlfeld JM, Vogel-Claussen J, Biller H, Berliner D, Berschneider K, Tillmann HC, et al. Effect of lung deflation with indacaterol plus glycopyrronium on ventricular filling in patients with hyperinflation and COPD (CLAIM): a double-blind, randomised, crossover, placebo-controlled, single-centre trial. Lancet Respir Med 2018;6:368-78.

77. Rennard SI. Clinical approach to patients with chronic ob- 
structive pulmonary disease and cardiovascular disease. Proc Am Thorac Soc 2005;2:94-100.

78. Divo MJ, DePietro MR, Horton JR, Maguire CA, Celli BR. Metabolic and cardiorespiratory effects of decreasing lung hyperinflation with budesonide/formoterol in COPD: a randomized, double-crossover, placebo-controlled, multicenter trial. Respir Res 2020;21:26.

79. Stone IS, Barnes NC, James WY, Midwinter D, Boubertakh R, Follows R, et al. Lung deflation and cardiovascular structure and function in chronic obstructive pulmonary disease: a randomized controlled trial. Am J Respir Crit Care Med 2016; 193:717-26

80. Vestbo J, Anderson JA, Brook RD, Calverley PM, Celli BR, Crim C, et al. Fluticasone furoate and vilanterol and survival in chronic obstructive pulmonary disease with heightened cardiovascular risk (SUMMIT): a double-blind randomised controlled trial. Lancet 2016;387:1817-26.

81. Lipson DA, Crim C, Criner GJ, Day NC, Dransfield MT, Halpin DMG, et al. Reduction in all-cause mortality with fluticasone furoate/umeclidinium/vilanterol in patients with chronic obstructive pulmonary disease. Am J Respir Crit Care Med 2020;201:1508-16.

82. Joo H, Han D, Lee JH, Rhee CK. Incidence of adverse effects and discontinuation rate between patients receiving $250 \mathrm{mi}-$ crograms and 500 micrograms of roflumilast: a comparative study. Tuberc Respir Dis 2018;81:299-304.

83. White WB, Cooke GE, Kowey PR, Calverley PM, Bredenbroker D, Goehring UM, et al. Cardiovascular safety in patients receiving roflumilast for the treatment of COPD. Chest 2013;144:758-65.

84. Evans RA. Developing the model of pulmonary rehabilitation for chronic heart failure. Chron Respir Dis 2011;8:259-69.

85. Long L, Mordi IR, Bridges C, Sagar VA, Davies EJ, Coats AJ, et al. Exercise-based cardiac rehabilitation for adults with heart failure. Cochrane Database Syst Rev 2019;1:CD003331.

86. Arnold MT, Dolezal BA, Cooper CB. Pulmonary rehabilitation for chronic obstructive pulmonary disease: highly effective but often overlooked. Tuberc Respir Dis 2020;83:257-67.

87. Gale NS, Duckers JM, Enright S, Cockcroft JR, Shale DJ, Bolton CE. Does pulmonary rehabilitation address cardiovascular risk factors in patients with COPD? BMC Pulm Med 2011;11:20.

88. Giannuzzi P, Temporelli PL, Corra U, Tavazzi L; ELVD-CHF Study Group. Antiremodeling effect of long-term exercise training in patients with stable chronic heart failure: results of the Exercise in Left Ventricular Dysfunction and Chronic Heart Failure (ELVD-CHF) Trial. Circulation 2003;108:554-9. 